\title{
Fluorine Substitution in Magnesium Hydride as a Tool for Thermody- namic Control
}

\author{
Terry D. Humphries, ${ }^{\text {a }}$ Jack Yang, ${ }^{\text {b,c }}$ Richard A. Mole, ${ }^{\mathrm{b}}$ Mark Paskevicius, ${ }^{\mathrm{a}}$ Julianne E. Bird, ${ }^{\mathrm{a}}$ Matthew \\ R. Rowles, ${ }^{\mathrm{a}, \mathrm{d}}$ Mariana S. Tortoza, ${ }^{\mathrm{a}}$ M. Veronica Sofianos, ${ }^{\mathrm{a}}$ Dehong Yu, ${ }^{\mathrm{b}}$ Craig. E. Buckley ${ }^{\mathrm{a}}$ \\ ${ }^{a}$ Physics and Astronomy, Fuels and Energy Technology Institute, Curtin University, GPO Box U1987, Perth, WA 6845, \\ Australia \\ ${ }^{\mathrm{b}}$ Australian Nuclear Science and Technology Organisation, Locked Bag 2001, Kirrawee DC NSW 2232 Australia \\ ${ }^{\mathrm{c}}$ School of Material Science and Engineering \& Advanced Materials and Manufacturing Futures Institute, University of New \\ South Wales, Sydney, New South Wales, 2052 Australia \\ d John De Laeter Centre, Curtin University, GPO Box U1987, Perth, WA 6845, Australia
}

\begin{abstract}
Metal hydrides continue to vie for attention as materials in multiple technological applications including hydrogen storage media, thermal energy storage (TES) materials and hydrogen compressors. These applications depend on the temperature at which the materials desorb and reabsorb hydrogen. Magnesium hydride is ideal as a TES, although its practical operating temperature is capped at $\sim 450{ }^{\circ} \mathrm{C}$ due to material degradation and high operating pressure. Fluorine substitution for hydrogen in magnesium hydride has previously been shown to increase the operating temperature of the metal hydride whilst limiting degradation, although full characterisation is required before technological application can be ensured. The present study characterises $\operatorname{Mg}\left(\mathrm{H}_{x} \mathrm{~F}_{l-x}\right)_{2}$ solid solutions $(x=1,0.95,0.70,0.85,0.50,0)$ by inelastic neutron spectroscopy, powder X-ray diffraction and thermal conductivity measurements, with the results being verified by density functional theory. For each experiment, a clear trend is observed throughout the series of solid-solutions, showing the possibility of tuning the properties of $\mathrm{MgH}_{2}$. As $\mathrm{F}^{-}$substitution increases, the average $\mathrm{Mg}-\mathrm{H}(\mathrm{F})$ bond distance elongates along the axial positions of the $\mathrm{Mg}-\mathrm{H}(\mathrm{F})$ octahedra. Overall this leads to an increase in $\mathrm{Mg}-\mathrm{H}$ bond strength and thermal stability, improving the viability of $\mathrm{Mg}-\mathrm{H}-\mathrm{F}$ as potential TES materials.
\end{abstract}

\section{INTRODUCTION}

For the global energy network to convert to a green hydrogen economy, four challenges must be met: (i) hydrogen production must primarily be from a renewable source; (ii) utilisation must be optimised including refuelling station infrastructure and fuel cells; (iii) hydrogen distribution must be safe and cost effective; and (iv) storage media for the hydrogen must be developed. There are a number of ways that hydrogen can be stored, including as a gas, cryogenic liquid, or chemically, e.g. within a metal hydride or ammonia. ${ }^{1,2}$ Metal hydrides, and in particular magnesium-based hydrides, have received enormous attention over the last 60 years for their potential as hydrogen storage materials. ${ }^{3-6}$ This has largely been due to the relatively high abundancy of magnesium metal in the Earth's crust and its relatively low cost of extraction. ${ }^{5}$ In addition, magnesium hydride has been shown to be highly reversible when used as a hydrogen storage material at a modest temperature. The binary hydride $\left(\mathrm{MgH}_{2}\right)$ has a theoretical hydrogen storage capacity of $7.7 \mathrm{wt} \%$ $\mathrm{H}_{2}$, but due to its relatively high enthalpy of hydrogen desorption of $74 \mathrm{~kJ} / \mathrm{mol} \mathrm{H}$ and entropy of $133 \mathrm{~J} / \mathrm{K} / \mathrm{mol}_{2} \mathrm{H}_{2}$, its operational temperatures are limited to only $300{ }^{\circ} \mathrm{C}$ at 1 bar $\mathrm{H}_{2}$ pressure, ${ }^{7}$ ensuring that $\mathrm{MgH}_{2}$ will never find technological application as a reversible fuel store for vehicular applications, as temperatures of $\sim 85{ }^{\circ} \mathrm{C}$ are preferred. ${ }^{8}$ As such, $\mathrm{MgH}_{2}$ has alternatively been considered as a material for thermal energy storage (TES) applications, such as storing heat from the sun to use at periods of weak solar irradiation, as a thermal battery. However, it cannot operate above $\sim 450{ }^{\circ} \mathrm{C}$ due to the tendency for magnesium to agglomerate, thus reducing its long term hydrogen storage capacity and also reducing the reaction kinetics. ${ }^{9}$

Many studies have been published in which issues with kinetics and agglomeration have been addressed by innovative approaches including nano-sizing, infiltration into porous scaffolds, and the incorporation of additives, including $\mathrm{TiB}_{2}$ as a particle refinement agent. ${ }^{4,5,9,10}$ All of these methods have proven successful in some regard and combinations of methods seem to be ideal. Recently, fluoride substitution for hydrogen in the $\mathrm{Mg}-\mathrm{H}$ system has been reported in which solid-solutions are synthesised by ball milling $\mathrm{MgH}_{2}$ and $\mathrm{MgF}_{2}$ in various ratios and also studied by density functional theory calculations. ${ }^{10-12}$ Fluorine substituted magnesium hydride solid solutions, $\mathrm{Mg}\left(\mathrm{H}_{x} \mathrm{~F}_{1-x}\right)_{2}$, were deemed to be stabilised compared to pure $\mathrm{MgH}_{2}$ and attributed to the positive enthalpy of mixing $\left(\triangle \mathrm{H}_{m i x}\right.$ $>0){ }^{11}$

The decomposition temperature of $\mathrm{Mg}\left(\mathrm{H}_{x} \mathrm{~F}_{1-x}\right)_{2}$ was determined via simultaneous differential scanning calorimetry - thermogravimetry (DSC-TGA) and powder X-ray diffraction (XRD) experiments. In addition, the thermodynamics of hydrogen release for $\mathrm{Mg}\left(\mathrm{H}_{0.85} \mathrm{~F}_{0.15}\right)_{2}$ were determined to be $73.6 \mathrm{~kJ} / \mathrm{mol} . \mathrm{H}_{2}$ and 131.2 $\mathrm{J} / \mathrm{K} / \mathrm{mol} \mathrm{H}_{2}$ close to that of pure $\mathrm{MgH}_{2}$. Interestingly, this material was shown to cycle at high temperatures, between 425 and $480{ }^{\circ} \mathrm{C}$. Despite the determination of these physical properties, little else is known regarding the fluorine substituted materials, although a smattering of analysis techniques have been used to study the physical properties of pure $\mathrm{MgH}_{2}$ (other than 
thermodynamics and kinetics) including powder neutron and Xray diffraction, ${ }^{13}$ NMR spectroscopy, ${ }^{14,}{ }^{15}$ vibrational spectroscopy $^{16-20}$ and thermal conductivity. ${ }^{21,22}$

With $\mathrm{Mg}\left(\mathrm{H}_{0.85} \mathrm{~F}_{0.15}\right)_{2}$ showing favourable operating temperatures as a thermal energy storage material, additional exploration of the physical properties for $\operatorname{Mg}\left(\mathrm{H}_{x} \mathrm{~F}_{1-x}\right)_{2}$ solid solutions have herein been undertaken by inelastic neutron spectroscopy, powder X-ray diffraction and thermal conductivity measurement. In addition, DFT calculations have been performed to corroborate the inelastic neutron spectroscopy and powder Xray diffraction results. This has allowed a full comparison on the stability of fluorine substitution in magnesium hydride.

\section{EXPERIMENTAL SECTION}

2.1. Sample Preparation All manipulations of chemicals were undertaken in an argon atmosphere using an Mbraun Unilab glovebox to prevent air exposure and to minimise oxygen $\left(\mathrm{O}_{2}<\right.$ $1 \mathrm{ppm})$ and water $\left(\mathrm{H}_{2} \mathrm{O}<1 \mathrm{ppm}\right)$ contamination. $\mathrm{Mg}\left(\mathrm{H}_{x} \mathrm{~F}_{I-x}\right)_{2}$ $(x=1,0.95,0.85,0.70,0.50,0)$ samples were prepared by ball milling (BM) various ratios of $\mathrm{MgH}_{2}$ and $\mathrm{MgF}_{2}$ (Sigma-Aldrich, $>99.99 \%$ ) at room temperature. $\mathrm{MgH}_{2}$ powder (95 wt \% purity from Rietveld refinement of X-ray diffraction data) was synthesised by annealing Mg powder (Aldrich, >99\%) at 400 ${ }^{\circ} \mathrm{C}$ under 30 bar hydrogen pressure for 18 hours. The full synthesis description is found in ref ${ }^{10}$. $\mathrm{BM}$ of $\mathrm{MgH}_{2}$ and $\mathrm{MgF}_{2}$ was undertaken at $400 \mathrm{rpm}$ for 40 hours in an Across International Planetary Ball Mill (PQ-N04) with a ball-to-powder mass ratio of 50:1 using stainless steel vials and balls $(6$ and $8 \mathrm{~mm}$ in diameter) under an Ar atmosphere. After milling, samples were annealed under a hydrogen atmosphere of 60 bar at $450{ }^{\circ} \mathrm{C}$ for a period of 90 hours to form solid solutions.

2.2. Synchrotron X-ray Characterisations Synchrotron powder X-ray diffraction (SR-XRD) was performed on the Powder Diffraction beamline at the Australian Synchrotron in Melbourne, Australia. ${ }^{23}$ Without exposure to air, the $\operatorname{Mg}\left(\mathrm{H}_{x} \mathrm{~F}_{1-x}\right)_{2}$ powders were loaded into borosilicate or quartz capillaries (outer diameter $0.7 \mathrm{~mm}$, wall thickness $0.01 \mathrm{~mm}$ ) that were then, using graphite ferrules, mounted in $1 / 16$ " tube fittings connected to a gas manifold. One-dimensional SR-XRD patterns (monochromatic X-rays with $\lambda=1.0003896$ or $0.8263076 \AA$ ) were collected using a Mythen microstrip detector ${ }^{24}$ with an exposure time of $54 \mathrm{~s}$ per pattern. The wavelength and line shape parameters were calibrated against an external standard of $\mathrm{LaB}_{6}$ (NIST SRM660c). The capillaries were continuously oscillated through $120^{\circ}$ during exposure to improve powder averaging. Diffraction patterns were quantitatively analysed using the Rietveld refinement method ${ }^{25,26}$ with TOPAS software (BrukerAXS). ${ }^{27}$

\subsection{Inelastic Neutron Scattering Characterisations Inelastic} neutron scattering (INS) data were collected using the Pelican cold-neutron time-of-flight spectrometer located at the OPAL reactor Lucas Heights, Australia. Samples were mounted in rectangular, flat plate, aluminium sample cans, with the thickness optimised for a $10 \%$ scatter, i.e. to minimise multiple scattering. The sample cans were mounted at $45^{\circ}$ to the incident beam and placed in a vacuum chamber at room temperature. The instrument was aligned for $4.69 \AA$ neutrons and the choppers were run in a time focusing configuration at either 100 or $200 \mathrm{~Hz}$. The resolution at the elastic line was $135 \mu \mathrm{eV}$. An empty can was subtracted to determine the background contribution and the data was normalised using data collected with a vanadium standard that had the same geometry as the sample can. All data manipulations were performed using the freely available software Lamp. ${ }^{28}$ Data were collected as $\mathrm{S}(Q, \omega)$ [i.e. scattering cross-section as a function of scattering wavevectors $(Q)$ and phonon frequency $(\omega)$ ], and these were transformed to a generalised density of states using formula (1), where $k_{b}$ is Boltzmann's constant, $T$ is temperature and $\hbar$ is the reduced Planck's constant. $^{29}$

$g(\omega)=\int \frac{\omega}{Q^{2}} S(Q, \omega)\left(1-e^{\frac{-\hbar \omega}{k_{b}^{T}}}\right) \mathrm{d} Q$

2.4. Thermal Property Characterisation The thermal conductivity $\left(\lambda_{T C}\right)$, thermal diffusivity $(k)$ and the heat capacity per unit volume $(C)$ of 5 ratios of $\mathrm{F}^{-}$and $\mathrm{H}^{-}$in $\mathrm{Mg}\left(\mathrm{H}_{x} \mathrm{~F}_{1-x}\right)_{2}$ were measured using a TPS 500S (Hot Disk, Thermtest). Measurements were undertaken in an argon atmosphere at a constant ambient temperature, measured by a $\mathrm{K}$ type thermocouple. $1.5 \mathrm{~g}$ of $\operatorname{Mg}\left(\mathrm{H}_{x} \mathrm{~F}_{1-x}\right)_{2}(x=1,0.95,0.85,0.70,0.50,0)$ were pressed in a die (13 mm diameter) using a manual hydraulic press $(370 \mathrm{MPa}$ of pressure for 5 minutes). A nickel double-spiral sensor (2 mm radius), laminated by electrically insulating Kapton was firmly clamped co-centrically between the pellets. 10 measurements per sample were conducted, with 15 minutes in between each measurement to allow the sample and sensor to cool.

2.5. First-Principle Calculations Density Functional Theory (DFT) based lattice dynamic calculations were performed to complement the INS measurements in order to better understand the stability and bonding in $\mathrm{Mg}\left(\mathrm{H}_{x} \mathrm{~F}_{1-x}\right)_{2}$ systems. All DFT calculations were performed with $\mathrm{VASP}^{30}$ under a generalised gradient approximation (GGA) using the Perdew-Burke-Ernzerhof (PBE) functionals together with the projector augmented wave (PAW) potentials. ${ }^{31,32}$ The energy cut-off for planewave expansion was set to $500 \mathrm{eV}$. The minimum-energy configurations for $\mathrm{MgH}_{2}$ and $\mathrm{MgF}_{2}$ were optimised with a dense $(15 \times$ $15 \times 15)$ Monkhorst-Pack $K$-point mesh. For all subsequent phonon calculations, geometry optimisations were relaxed with an energy convergence of $10^{-7} \mathrm{eV}$ and forces less than $10^{-6}$ eV/atom.

In order to account for the statistically disordered nature of $\mathrm{F}$ substitution in $\mathrm{MgH}_{2}$, all unique configurations of F-substituted $\mathrm{MgH}_{2}$ supercells were sampled for calculating the corresponding thermodynamic stabilities and phonon density of states (DOS). Here, $\operatorname{Mg}\left(\mathrm{H}_{x} \mathrm{~F}_{1-x}\right)_{2}$ at different concentrations $(x=0.95$, $0.90,0.85,0.80,0.75,0.70$ and 0.50$)$ were simulated, which led to a total number of configurations of $34,33,30,27,26,2,2$, respectively, for each nominated $\mathrm{F}$ concentration. Supercells of sizes $(1 \times 1 \times 1)$ [for $x=0.50],(5 \times 1 \times 1)$ and $(1 \times 1 \times 5)$ [for all other fluoride concentrations] were used with corresponding Monkhorst-Pack $K$-point meshes of $(6 \times 6 \times 9),(2 \times$ $6 \times 6)$ and $(6 \times 6 \times 2)$, respectively. Because $\mathrm{MgH}_{2}$ adopts an orthorhombic lattice, supercell expansions along both the $a$ and $c$ axis were considered, as well as several possible unique $\mathrm{F}^{-}$ positions at a given $x$ and supercell size. Thermodynamic stabilities (formation energies $\Delta E_{f}$ ) for the substituted structure were modelled according to the following reaction:

$\mathrm{Mg}+x \mathrm{H}_{2}+(1-x) \mathrm{F}_{2} \rightarrow \mathrm{Mg}\left(\mathrm{H}_{x} \mathrm{~F}_{1-x}\right)_{2}$

Such that:

$$
\begin{aligned}
& \Delta E_{f}=E\left[M g\left(H_{x} F_{1-x}\right)_{2}\right]-E[M g]-x E\left[H_{2}\right]- \\
& (1-x) E\left[F_{2}\right]
\end{aligned}
$$


where $E$ is the total energy from DFT calculations that contains both the ionic and electronic contributions.

Phonon DOS were calculated using a finite-displacement method as implemented in PHONOPY interfaced with VASP. ${ }^{33}$ For $\mathrm{Mg}\left(\mathrm{H}_{x} \mathrm{~F}_{1-x}\right)_{2}$ systems simulated with different supercells, the corresponding supercells and $K$-point meshes used in phonon calculations are summarised in Table 1.

The theoretically calculated phonon DOS were subsequently rescaled to consider the differences in the inelastic neutron scattering cross sections for different elements, as adopted by Bansal et al., ${ }^{34}$ where the neutron weighted DOS was calculated according to the following formula:

$G=\sum_{i} \frac{\sigma_{i}}{m_{i}} g_{i} / N_{t o t}$

Here $\sigma_{i}$ is either the coherent and incoherent neutron scattering cross-section for the $i^{\text {th }}$ element, $m_{i}$ is the corresponding atomic mass, $g_{i}$ is the partial phonon density-of-states for the $i$ th element and $N_{\text {tot }}$ is the total number of atoms in the supercell. ${ }^{35}$ To effectively compare the phonon DOS across systems with different $\mathrm{F}$ concentrations, the phonon DOS at any given $\mathrm{F}$ concentration was averaged across all supercell configurations $\left(N_{\text {config }}\right)$ considered at that concentration according to:

$\overline{\operatorname{DOS}(E)}=\frac{1}{N_{\text {config }}} \sum_{i=1}^{N_{\text {config }}} \operatorname{DOS}_{i}(E)$

No additional weighting parameter, such as the relative stabilities of different configurations (at a fixed $\mathrm{F}$ concentration) was used, because the differences in the calculated formation energies were almost negligible [see the Results section].

Table 1. Supercells and $K$-point meshes chosen for finite-displacement phonon calculations in VASP. Also shown is the $\boldsymbol{\Gamma}$ centred $K$-point grids used for phonon density-of-states integrations. Note that the supercell for phonon simulations were specified with respect to the supercells for calculating the substitution formation energies, not the primitive $\mathrm{MgH}_{2}$ unit cell.

$\begin{array}{cccc}\begin{array}{c}\text { Defect } \\ \text { supercell }\end{array} & \begin{array}{c}\text { Phonon } \\ \text { supercell }\end{array} & \begin{array}{c}\text { Phonon K- } \\ \text { point meshes }\end{array} & \begin{array}{c}\text { DOS integra- } \\ \text { tion grid }\end{array} \\ 1 \times 1 \times 1 & 3 \times 3 \times 3 & 2 \times 2 \times 3 & 20 \times 20 \times 20 \\ 5 \times 1 \times 1 & 1 \times 2 \times 2 & 2 \times 3 \times 3 & 10 \times 10 \times 10 \\ 1 \times 1 \times 5 & 2 \times 2 \times 1 & 3 \times 3 \times 2 & 10 \times 10 \times 10\end{array}$

\section{RESULTS AND DISCUSSION}

3.1 Powder X-ray diffraction $\mathrm{MgH}_{2}$ and $\mathrm{MgF}_{2}$ both exist in the aristotypic rutile-type structure in space group $P 4_{2} / \mathrm{mnm}$. The lattice parameters measured after ball milling and annealing in this study are provided in Tables 2 and $\mathrm{S} 1$. These values agree with the literature values for $\mathrm{MgH}_{2}$ and $\mathrm{MgF}_{2}$, respectively. ${ }^{36,}{ }^{37}$ Despite the larger covalent character exhibited by $\mathrm{MgH}_{2}$, the lattice parameters for $\mathrm{MgH}_{2}$ are smaller than that observed for $\mathrm{MgF}_{2}{ }^{12,38,39}$ Along with the fact that $\mathrm{MgF}_{2}$ is significantly more stable than $\mathrm{MgH}_{2}$, it is expected that $\mathrm{Mg}-\mathrm{F}$ bonds be shorter. In fact, the axial $\mathrm{Mg}-\mathrm{H}$ bond distances are 1.935973(6) $\AA$ compared to 1.98114(2) $\AA$ for the equivalent $\mathrm{Mg}-\mathrm{F}$ bonds. Since $\mathrm{F}^{-}$is highly electronegative, it will also form small covalent interactions between neighbouring $\mathrm{F}^{-}$, which not only creates further stabilisation, but allows the $\mathrm{Mg}-\mathrm{F}$ bond distance to increase. ${ }^{12}$ This has been illustrated using electron density maps derived from theoretical calculations and X-ray diffraction measurements. ${ }^{12,}{ }^{39,}{ }^{40} \mathrm{In} \mathrm{MgF}_{2}$, electron density between the $\mathrm{F}^{-}$atoms is observed, while most of the electron density has been withdrawn from the $\mathrm{Mg}^{2+}$ by the $\mathrm{F}^{-}$. In $\mathrm{MgH}_{2}$, some anisotropic charge distribution between the $\mathrm{Mg}$ and $\mathrm{H}$ and $\mathrm{H}$ atoms suggesting partial covalency. ${ }^{12}$

From Table 2 it can be seen that the greatest difference in lattice parameters is experienced in the $a$-axis of the unit cell with a $2.3 \%$ decrease from $\mathrm{MgF}_{2}$ to $\mathrm{MgH}_{2}$ compared to $1.0 \%$ in the $c$ axis. This manifests into an overall decrease in unit cell volume of $5.4 \%$ for $\mathrm{MgH}_{2}$. The anisotropic nature of the lattice parameters points to the stability of the octahedral chains that run in the direction of the $c$-axis (Figure 1). ${ }^{36}$ These chains, with four coplanar equatorial $\mathrm{Mg}-\mathrm{H}(\mathrm{F})$ bonds, are connected via cornersharing with four symmetrically equivalent chains, and are therefore quite stable. Thus there is only a $1.5 \%$ change in the equatorial $\mathrm{Mg}-\mathrm{H}(\mathrm{F})$ bonds compared to $2.3 \%$ for the axial $\mathrm{Mg}-\mathrm{H}(\mathrm{F})$ bonds.

Upon ball milling and annealing $\mathrm{MgH}_{2}$ and $\mathrm{MgF}_{2}$ in varying ratios (Table 2), $\mathrm{Mg}\left(\mathrm{H}_{x} \mathrm{~F}_{1-\mathrm{x}}\right)_{2}(x=1,0.95,0.85,0.70,0.50,0)$ was produced. No peak splitting was observed in the diffraction patterns, indicating that solid solutions were formed. ${ }^{10}$ The lattice parameters, and by association, unit cell volume and bond distances increase with increasing $\mathrm{F}^{-}$content, with each following a quadratic trend. Analysis was undertaken by quantitative Rietveld refinement of the SR-XRD data using Topas (illustrated in Figure S1 and Table S1). ${ }^{27}$ Fifteen individual

Table 2. Structural properties of $\mathrm{Mg}\left(\mathrm{H}_{x} \mathrm{~F}_{1-x}\right)_{2}(x=1,0.95,0.85,0.70,0.50,0)$ materials measured by SR-XRD at room temperature. Estimated standard deviations (esd's) are in parentheses.

\begin{tabular}{|c|c|c|c|c|}
\hline \multirow[b]{2}{*}{ Sample name } & \multicolumn{2}{|c|}{ Lattice parameter $(\AA)$} & \multicolumn{2}{|c|}{$\mathbf{M g}-\mathbf{H}(\mathbf{F})(\AA)$} \\
\hline & $\mathbf{a}$ & c & Axial & Equatorial \\
\hline \multirow[t]{2}{*}{$\mathrm{MgH}_{2}$} & $4.51795(1)$ & $3.02257(1)$ & $1.935976(6)$ & $1.966804(5)$ \\
\hline & $4.516(8)^{\mathrm{a}}$ & $3.020(5)^{\mathrm{a}}$ & --- & --- \\
\hline $\mathrm{Mg}\left(\mathrm{H}_{0.95} \mathrm{~F}_{0.05}\right)_{2}$ & $4.52458(1)$ & $3.02345(1)$ & $1.946(3)$ & $1.964(2)$ \\
\hline $\operatorname{Mg}\left(\mathrm{H}_{0.85} \mathrm{~F}_{0.15}\right)_{2}$ & $4.54284(1)$ & $3.02982(1)$ & $1.946637(4)$ & $1.974028(4)$ \\
\hline $\mathrm{Mg}\left(\mathrm{H}_{0.70} \mathrm{~F}_{0.30}\right)_{2}$ & $4.56514(4)$ & $3.04023(3)$ & $1.95619(2)$ & $1.98201(1)$ \\
\hline $\mathrm{Mg}\left(\mathrm{H}_{0.50} \mathrm{~F}_{0.50}\right)_{2}$ & $4.59225(3)$ & $3.04441(2)$ & $1.9716(8)$ & $1.9860(5)$ \\
\hline \multirow[t]{2}{*}{$\mathrm{MgF}_{2}$} & $4.62337(5)$ & $3.05214(5)$ & $1.98114(2)$ & $1.99700(2)$ \\
\hline & $4.6249(1)^{\mathrm{b}}$ & $3.0520(1)^{\mathrm{b}}$ & --- & --- \\
\hline
\end{tabular}


(a)

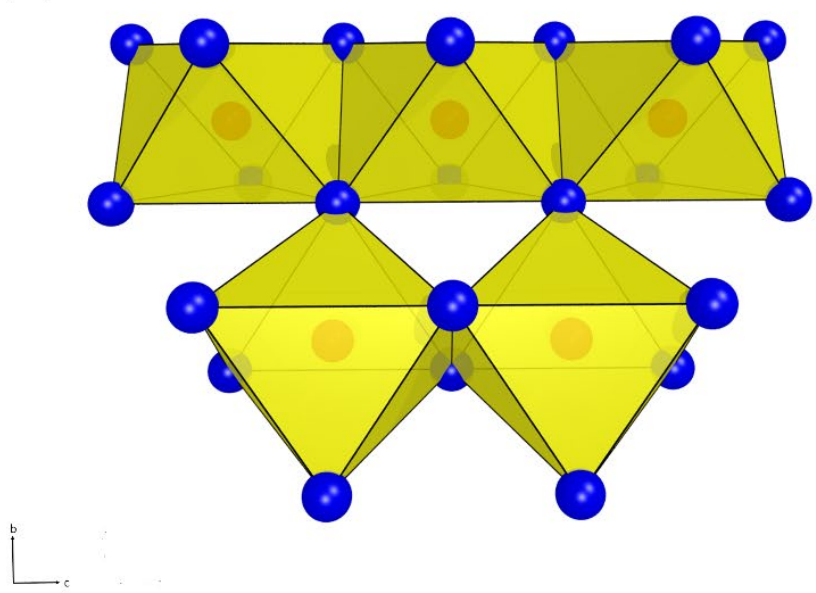

(b)

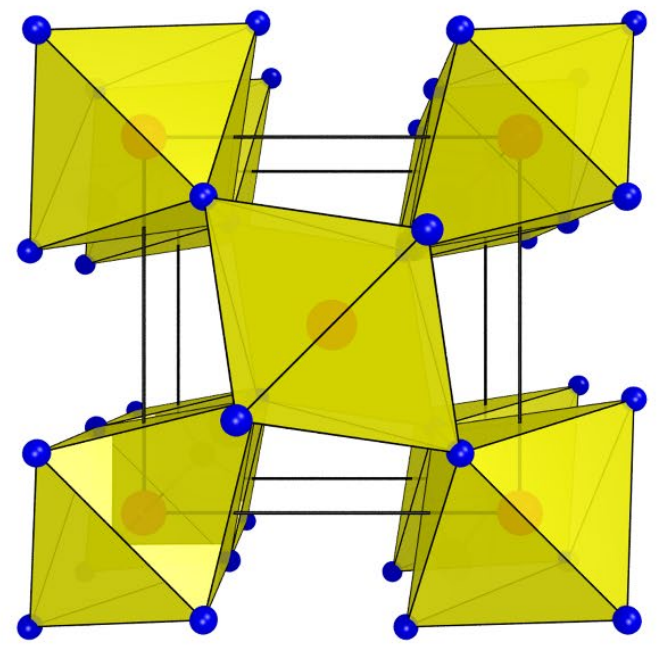

Figure 1. Representative views of $\mathrm{Mg}\left(\mathrm{H}_{x} \mathrm{~F}_{1-\mathrm{x}}\right)_{2}$; (a) $\mathrm{Mg}-\mathrm{H}(\mathrm{F})_{6}$ octahedral units viewed along the $a$-axis and (b) along the $c$ axis. $\mathrm{Mg}$ atoms represented as red spheres, $\mathrm{H}(\mathrm{F})$ atoms as blue spheres and $\mathrm{Mg}-\mathrm{H}(\mathrm{F})_{6}$ octahedra represented with yellow faces.
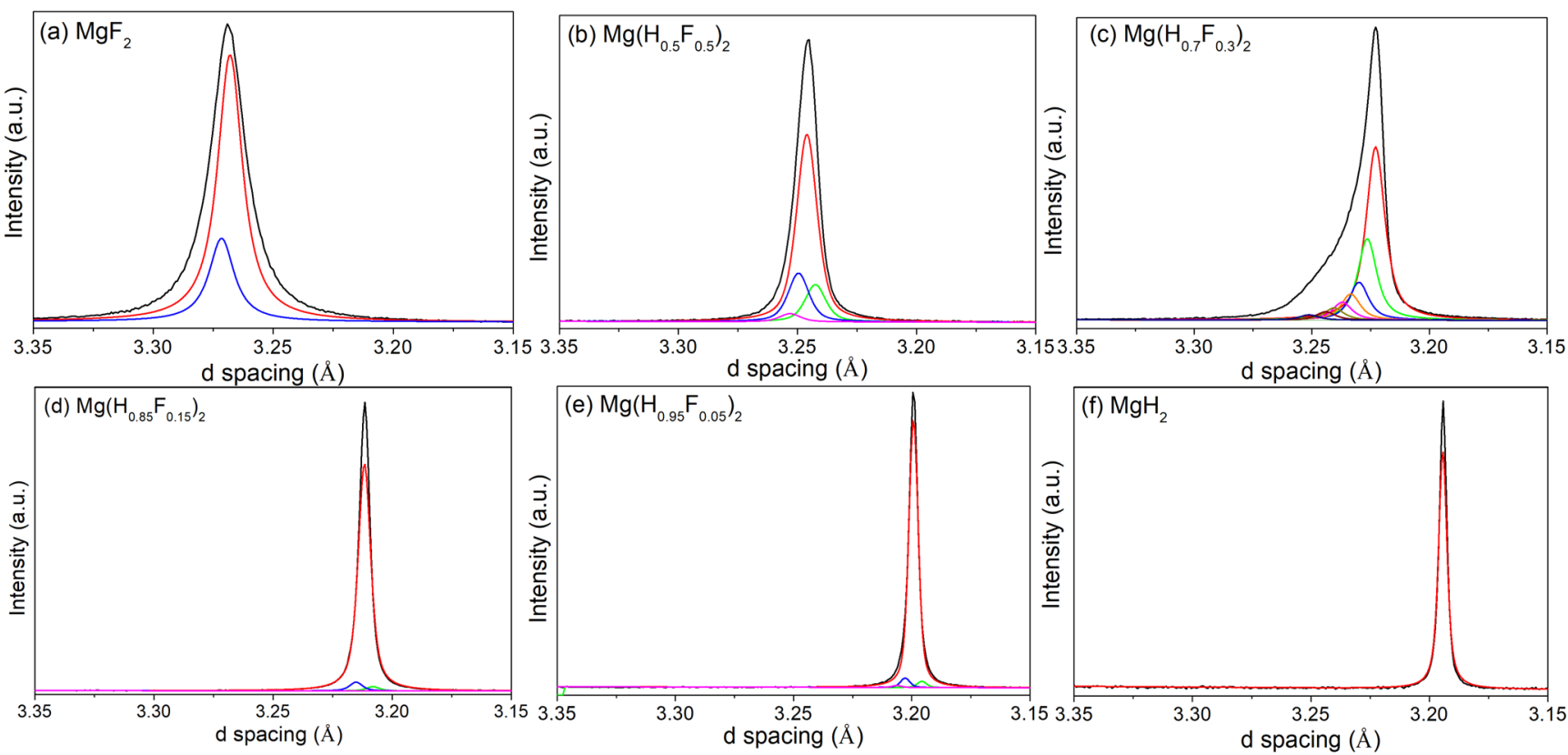

Figure 2. Phase distribution in $\mathrm{Mg}\left(\mathrm{H}_{x} \mathrm{~F}_{1-x}\right)_{2}$ solid solutions determined by SR-XRD as observed at the (110) Bragg peak. $T=27{ }^{\circ} \mathrm{C}$.

$\operatorname{Mg}\left(\mathrm{H}_{x} \mathrm{~F}_{1-x}\right)_{2}$ structure phases ( 11 for $\mathrm{MgH}_{0.85} \mathrm{~F}_{0.15}$ ) were refined allowing the lattice parameters to refine freely and $\mathrm{H} / \mathrm{F}$ occupancy was calculated from the lattice parameters assuming Vegards Law. ${ }^{41}$ The fractional atomic coordinate of $\mathrm{H} / \mathrm{F}$ in the $4 f$ position was fixed at 0.303 as it did not move significantly during refinement.

Table 2 details the weight averaged lattice parameters, while Figure 2 illustrates the data by focusing on the (110) Bragg peak. The lattice parameters of each phase are detailed in Table S1) Phase segregation is apparently minimal for all samples, which is in contrast with a recent study on $\mathrm{NaH}_{x} \mathrm{~F}_{1-x}(x=1,0.95$, $0.85,0.70,0.50,0)$, where a statistical distribution of phases was observed after annealing for 6 days. ${ }^{42}$ The only sample exhibiting a large dispersion of phases was $\mathrm{Mg}\left(\mathrm{H}_{0.70} \mathrm{~F}_{0.3}\right)_{2}$, which is most likely due to insufficient annealing during synthesis.
The tail of the peak tends towards higher $d$ spacing of which is indicative of a large spread of phases with increased $\mathrm{F}^{-}$content.

Each of these solid solutions was modelled using DFT in order to complement the XRD and INS data. The optimised DFT supercells were first analysed to ensure that the unit cell parameters and bond distances agreed with the experimental data. Table S2 details the unit cell volumes, lattice parameters and bond distances for the supercells and compares them to the experimental data. For each of the parameters a similar trend observed between the calculated and measured data sets. In addition, each of the respective experimental and theoretical data sets agree to within $3.1 \%$, of which the largest deviation is for the $\mathrm{MgF}_{2}$ unit cell volume. Overall, the significant agreement suggests that the calculated DFT data represents a quality model to fit against the INS data. 

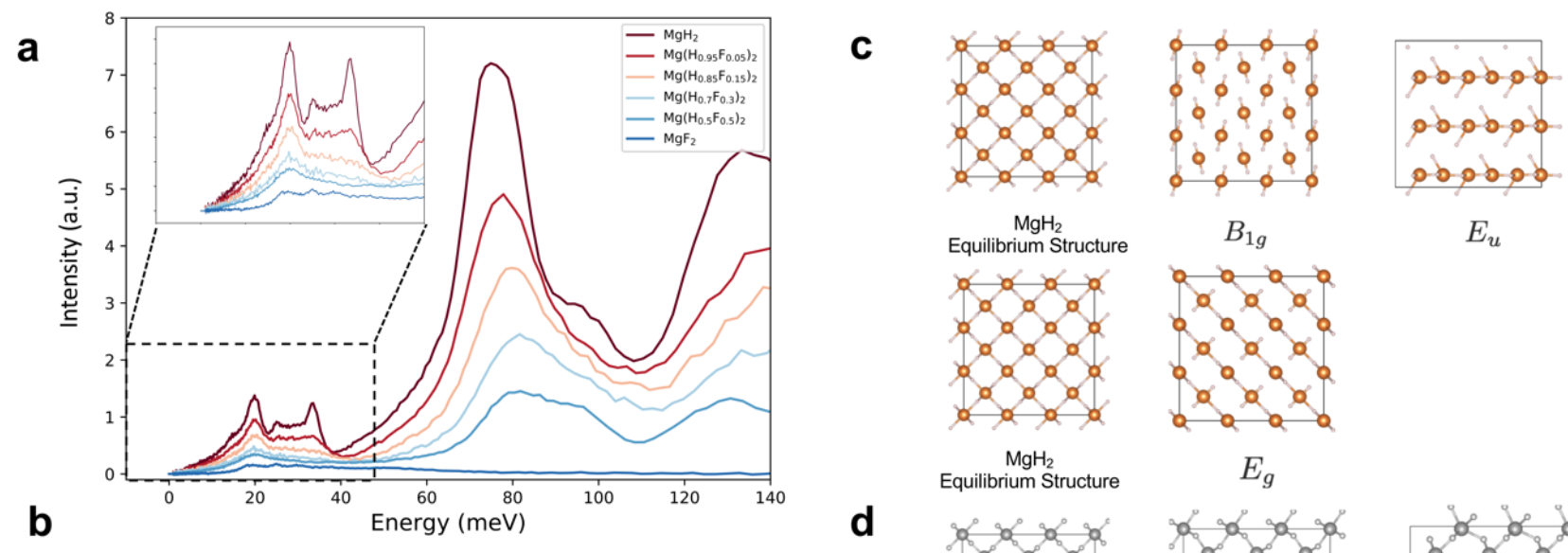

$$
B_{1 g}
$$

$E_{u}$ $a_{a}^{a} a b_{a}^{a}$
$a a_{a} a_{a}$
$a_{a} a_{a} b_{a}$

$\mathrm{MgH}_{2}$

$\stackrel{\mathrm{MgH}_{2}}{\text { Equilibrium Structure }}$

$$
E_{g}
$$
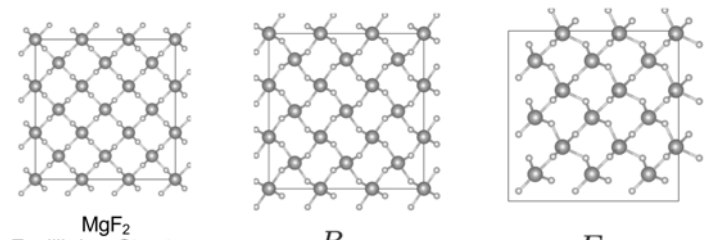

Equilibrium Structure

$$
B_{1 g}
$$

$E_{u}$

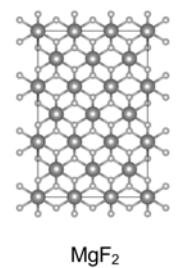

$\frac{\mathrm{MgF}_{2}}{\text { Equilibrium Structure }}$
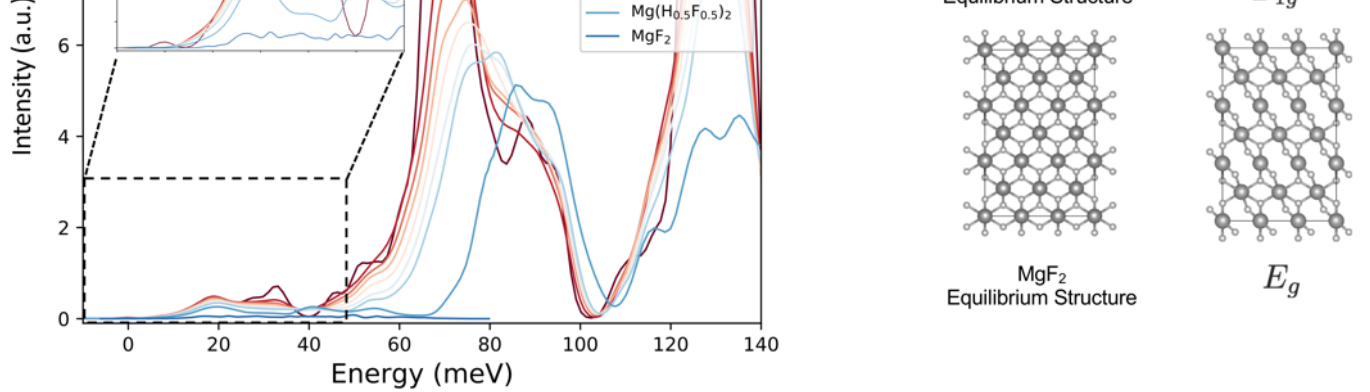

Figure 3. Phonon density-of-states of $\mathrm{Mg}\left(\mathrm{H}_{x} \mathrm{~F}_{1-x}\right)_{2}$ solid solutions determined by (a) INS (intensity is normalised) and (b) DFT-based lattice dynamic calculations. For calculated data the contributions from different constituent atoms are weighted by their corresponding inelastic neutron scattering cross-sections. For $\mathrm{MgF}_{2}$, there are no phonon branches beyond $80 \mathrm{meV}$. Insets show the enlarged low-energy part of the phonon density-of-states. (c-d) show the pattern of atomic vibrations for the $B_{l g}, E_{u}$ and $E_{g}$ phonon modes for $\mathrm{MgH}_{2}$ and $\mathrm{MgF}_{2}$.

3.2. Inelastic Neutron Spectroscopy The INS spectra, for each of the $\mathrm{Mg}-\mathrm{H}-\mathrm{F}$ compositions, were measured to determine the similarities in the structural dynamics between the solid solutions and pure components (Figure 3). The spectrum for $\mathrm{MgH}_{2}$ agrees with previously reported ones. ${ }^{17,} 18$ There are three low intensity vibrations below $40 \mathrm{meV}$ at 20,25 and $33\left(B_{l g}\right) \mathrm{meV}$, which have been previously ascribed primarily to in-phase vibrations of hydrogen atoms with in-phase vibrations of the $\mathrm{Mg}$ atoms (lattice vibrations). ${ }^{17}$ The broad mode between $60-105$ $\mathrm{meV}$ is described as H-related $E_{u}$ optic modes, which are threefold degenerated, and the large widths suggest a large dispersion of the optic phonon branches and consequently strong $\mathrm{H}-$ $\mathrm{H}$ interactions. ${ }^{17}$ Above $105 \mathrm{meV}$, a very broad region is observed that is attributed to the $E_{g}$ mode, which is a two-fold degenerate mode that corresponds to the asymmetric bending of the $\mathrm{H}(\mathrm{F})-\mathrm{Mg}-\mathrm{H}(\mathrm{F})$ bond (equatorial) in the [001] plane parallel to the $c$-axis. ${ }^{43} \mathrm{~A}$ schematic illustration of these three vibrational modes for $\mathrm{MgH}_{2}$ and $\mathrm{MgF}_{2}$ is shown in Figures 3(c) and 3(d). To complement the INS results, DFT-based lattice dynamics were applied to model the generalised phonon density-of-states (GDOS). Upon weighting the results with the inelastic neutron scattering cross-sections for different elements, Figure 3(b) shows an excellent agreement between theoretical GDOS and INS spectrum for $\mathrm{MgH}_{2}$. This validates our theoretical calculations, which allows us to extract useful information for understanding the influence of $\mathrm{F}^{-}$doping on the lattice dynamics for the systems as probed by the INS experiments. Notice that under harmonic approximations, GDOS for $\mathrm{MgH}_{2}$ shows a small non-vanishing GDOSat negative phonon energies, suggesting that $\mathrm{MgH}_{2}$ is anharmonic and thus $\mathrm{MgH}_{2}$ is thermally stabilised at $300 \mathrm{~K}$. Such a feature is not observed in all $\mathrm{F}^{-}$doped structures.

As $\mathrm{F}^{-}$content in the solid solution increases, a number of changes to the INS spectra are observed. The vibration at 33 $\mathrm{meV}$ becomes broader and almost vanishes along with the peak at $25 \mathrm{meV}$, while the vibration at $20 \mathrm{meV}$ remains. This can be attributed to the fact that the $B_{l g}$ mode for $\mathrm{MgF}_{2}$ is much softer than that of $\mathrm{MgH}_{2}$, which occurs at around $9.1 \mathrm{meV}$, as revealed by lattice dynamic calculations. The most intense peak at 75 meV gradually shifts to higher energy with higher $\mathrm{F}^{-}$content, to $83 \mathrm{meV}$ for $\mathrm{MgH}_{0.50} \mathrm{~F}_{0.50}$, which also agrees well with GDOS obtained from lattice dynamic calculations. Atomic vibrations within this energy range are typically dominated by the optical $E_{u}$ modes Figure 3(c) arising from the vibrations of $\mathrm{H}$ sublattices, an upshift in the energy thus indicates this mode is significantly stiffened by the addition of fluorine in the system. Such a shift in the frequencies of optical phonon reflects the enhancement of ionicity in the $\operatorname{Mg}\left(\mathrm{H}_{x} \mathrm{~F}_{1-x}\right)_{2}$ with increasing fluoride content, as $\mathrm{F}^{-}$is of larger electronegativity to hydrogen, which consequently draws more electrons from $\mathrm{Mg}$ compared to $\mathrm{H}^{-}$. 


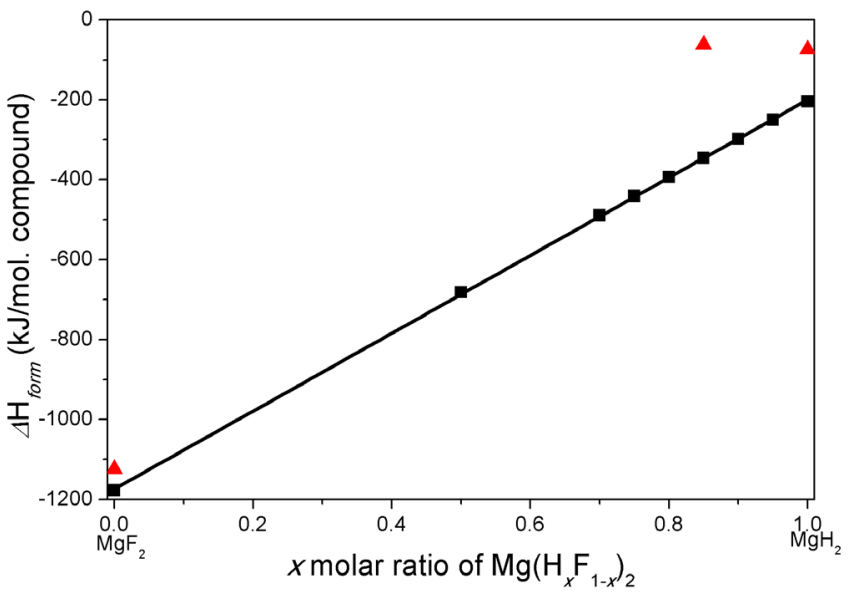

Figure 4. Formation energies for $\mathrm{Mg}\left(\mathrm{H}_{x} \mathrm{~F}_{1-x}\right)_{2}$. Black squares correspond to DFT calculated formation energies, red triangles correspond to experimentally derived formation energies. . $^{70,44}$

3.3. Thermodynamics of $\mathbf{M g}\left(\mathbf{H}_{x} \mathbf{F}_{1-x}\right)_{2}$ DFT modelling enables the extraction of more information than just the phonon densityof-states, with formation energy $\left(\Delta H_{\text {form }}\right)$ of $\mathrm{Mg}\left(\mathrm{H}_{x} \mathrm{~F}_{1-x}\right)_{2}$ solid solutions being an indicator for material stability. Figure 4 and Table S3 illustrate a linear trend with $\Delta H_{\text {form }}$ becoming more negative as the concentration of $\mathrm{F}^{-}$increases in $\mathrm{Mg}\left(\mathrm{H}_{x} \mathrm{~F}_{1-x}\right)_{2}$. As such, the theoretical $\Delta H_{\text {form }}$ for $\mathrm{MgH}_{2}$ and $\mathrm{MgF}_{2}$ is -204 and $-1178 \mathrm{~kJ} / \mathrm{mol}$ of compound, respectively. This indicates that as $\mathrm{F}^{-}$substitution increases so does the thermal stability of the compound.

Experimental thermodynamic data do not mirror this trend. Although the experimental and DFT calculated $\Delta H_{\text {form }}$ for $\mathrm{MgF}_{2}$ differs by only $4.5 \%$ (experimental $\Delta H_{\text {form }}=-1124 \mathrm{~kJ} / \mathrm{mol}$ of compound $),{ }^{44}$ the DFT value for $\mathrm{MgH}_{2}$ is $175 \%$ the magnitude of the experimentally determined value of $-74.06 \pm 0.42$ $\mathrm{kJ} / \mathrm{mol}^{7}$ These two data points do suggest that $\Delta H_{\text {form }}$ becomes more negative with $\mathrm{F}^{-}$content, but the experimental value for $\mathrm{Mg}\left(\mathrm{H}_{0.85} \mathrm{~F}_{0.15}\right)_{2}$ of $-62.6 \pm 0.2 \mathrm{~kJ} / \mathrm{mol}$ does not follow a linear trend and actually becomes less negative compared to $\mathrm{MgH}_{2}$.

The experimental $\Delta H_{\text {form }}$ for $\mathrm{MgH}_{2}$ and $\mathrm{Mg}\left(\mathrm{H}_{0.85} \mathrm{~F}_{0.15}\right)_{2}$ is derived from the enthalpy of hydrogen desorption $\left(\Delta H_{d e s}\right)$ determined by PCI (Pressure-concentration isotherm) analysis. Therefore an assumption must be made in that there is no pressure hysteresis between the absorption and desorption process. For these particular materials, hysteresis has been shown not to occur and any artefact is likely due to the slow kinetics of the reaction process. ${ }^{7}{ }^{10}$ As such these values can be expressed as $\Delta H_{\text {form }}$. Pressure-concentration isotherm (PCI) analysis is the ideal method to determine the thermodynamics associated with the reaction of hydrogen release, in which the enthalpic and entropic contributions can be individually identified using a van't Hoff plot. ${ }^{45}$ Unfortunately, PCI analysis has only been conducted on pure $\operatorname{MgH}_{2}\left(\Delta H_{\text {des }}=74.06 \pm 0.42 \mathrm{~kJ} / \mathrm{mol} ; \Delta S_{\text {des }}=\right.$ $133.4 \pm 0.7 \mathrm{~J} / \mathrm{K} / \mathrm{mol})^{7}$ and $\mathrm{Mg}\left(\mathrm{H}_{0.85} \mathrm{~F}_{0.15}\right)_{2}\left(\Delta H_{\text {des }}=62.6 \pm 0.2\right.$ $\left.\mathrm{kJ} / \mathrm{mol} ; \Delta S_{\text {des }}=111.5 \pm 0.2 \mathrm{~J} / \mathrm{K} / \mathrm{mol}\right) .{ }^{10}$ Although at first glance, the magnitude of $\Delta H_{d e s}$ and $\Delta S_{d e s}$ are both observed to decrease with increasing $\mathrm{F}^{-}$content, which seems to be counterintuitive when claiming the system is becoming stabilised. However, the magnitude of $\Delta S_{\text {des }}$ decreases to a larger extent than the magnitude of $\Delta H_{d e s}$, resulting in $\Delta G_{d e s}$ becoming lessnegative as $\mathrm{F}^{-}$content increased, implying that decomposition will occur at higher temperatures when under the same back pressure of $\mathrm{H}_{2}$. In short, $\Delta S_{\text {des }}$ has a larger impact on the temperature of decomposition than $\Delta H_{\text {des }}$.

The difference between the DFT and experimentally determined enthalpy of formation may be attributed to the reaction pathways employed when determining $\Delta H_{\text {form }}$. DFT calculations assume direct formation from the elements, whereas the measured values are determined based on the reversible reaction displayed in equation (2). The endothermic $\Delta H_{\text {des }}$ determined by PCI experiments includes the formation of pure $\mathrm{MgF}_{2}$ of which is an exothermic reaction. Therefore, the exothermic formation of additional $\mathrm{Mg}-\mathrm{F}$ bonds reduces the overall measured $\Delta H_{\text {des. }}$ During the formation of $\mathrm{Mg}\left(\mathrm{H}_{x} \mathrm{~F}_{1-x}\right)_{2}$ from $\mathrm{MgF}_{2}+$ $\mathrm{Mg}$ the endothermic contribution encountered during the breaking of $\mathrm{Mg}-\mathrm{F}$ bonds therefore decreases the $\Delta H_{\text {form }}$ compared to that expected if formed from the elements. As a result, $\Delta H_{\text {form }}$ determined by DFT calculations would be more negative than those determined experimentally.

The increased thermal stability with increasing $\mathrm{F}^{-}$content has been demonstrated using DSC-TGA and as such the temperature of decomposition is a better measure of thermal stability than using $\Delta H_{\text {form }}$ calculated using DFT alone. In this study, $\Delta H$ form was calculated at $0 \mathrm{~K}$ and therefore it is impossible to estimate the temperature of decomposition using these calculations, although it does provide a good qualitative estimate of stability. $\Delta S_{\text {form }}$ must be calculated in order to determine the temperature of formation/decomposition. The enthalpy and entropy determined by PCI analysis the temperature of formation under 1 bar $\mathrm{H}_{2}$ to be 282 and $288{ }^{\circ} \mathrm{C}$ for $\mathrm{MgH}_{2}$ and $\mathrm{MgH}_{0.85} \mathrm{~F}_{0.15}$, respectively $(\Delta G=\Delta H-T \Delta S$, where $\Delta G=0)$.

3.4. Thermal Transport Properties of $\operatorname{Mg}\left(\mathrm{H}_{x} \mathrm{~F}_{1-x}\right)_{2}$ If these $\mathrm{Mg}\left(\mathrm{H}_{x} \mathrm{~F}_{1-x}\right)_{2}$ compounds are to be implemented as thermal energy storage materials, the thermal properties must be determined. The thermal transport properties of the $\operatorname{Mg}\left(\mathrm{H}_{x} \mathrm{~F}_{1-x}\right)_{2}$ compounds are presented in Table 3. A non-linear relationship exists between the thermal transport properties and amount of $\mathrm{H} / \mathrm{F}$ present (Figure 5). The data collected for $\mathrm{MgF}_{2}$ of $0.676(6)$ $\mathrm{W} / \mathrm{m} . \mathrm{K}$ is lower than that measured in the literature of 11.6 $\mathrm{W} / \mathrm{m} . \mathrm{K}^{46}{ }^{46}$ The measurement of thermal transport properties are highly susceptible towards sample preparation and measurement conditions, in this study the samples were measured as a pelletised powder $(370 \mathrm{MPa})$, while a pre-melted $\mathrm{MgF}_{2}$ pellet was used previously leading to an increased $\lambda_{T C}$. The results provided here are all self-consistent and comparable due to the identical sample preparation.

The thermal conductivity of $\mathrm{MgH}_{2}$ was measured in this study as $2.08(3) \mathrm{W} / \mathrm{m} . \mathrm{K}$, where $k=1.53(7) \mathrm{mm}^{2} / \mathrm{s}$ and $C=1.37(8)$ $\mathrm{MJ} / \mathrm{m}^{3} \cdot \mathrm{K}$. $\lambda_{T C}$ measured in this study is therefore reasonably close with literature values of $0.40-1.21 \mathrm{~W} / \mathrm{m} . \mathrm{K} \cdot{ }^{21,47,48}$ The literature values were obtained from samples measured as a pellet pressed at a pressure of $100 \mathrm{MPa}$ with a $\lambda_{T C}=0.70 \mathrm{~W} / \mathrm{m} \cdot \mathrm{K}$ being determined, ${ }^{21}$ while additional cold rolling enabled a measurement of $1.21 \mathrm{~W} / \mathrm{m} . \mathrm{K}^{48}$ The variation in results is therefore attributed to the effect of sample preparation conditions. Thermal properties are enhanced by phonon interactions, ${ }^{49}$ hence smaller particle size, increased pressure and pre-melting enhance thermal transport properties. The sample measurements in this study were conducted under identical conditions under an $\mathrm{Ar}$ atmosphere. Thermal conductivity and diffusivity decrease with increasing $\mathrm{F}^{-}$content, and is at a minima for $\mathrm{MgH}_{0.5} \mathrm{~F}_{0.5}$, before a slight increase is observed for $\mathrm{MgF}_{2}$. The heat capacity per unit volume of these materials appears to vary between $1.17(4)$ and $1.58(3) \mathrm{MJ} / \mathrm{m}^{3} \cdot \mathrm{K}$ with a specific trend not 
being observed. In fact, the values for the $\mathrm{F}^{-}$containing materials may be considered as being almost equivalent within error.

Overall, the $\lambda_{T C}$ for these F-substituted materials are highly comparable to other metal hydride materials. For instance $\lambda_{T C}=$ $0.96 \mathrm{~W} / \mathrm{m} \cdot \mathrm{K}$ for $\mathrm{NaBH}_{4},{ }^{50}$ and $0.06-4.5 \mathrm{~W} / \mathrm{m} \cdot \mathrm{K}$ for $\mathrm{NaAlH}_{4}$

Table 3. Thermal Transport Properties of $\mathrm{Mg}\left(\mathrm{H}_{x} \mathrm{~F}_{I-x}\right)_{2}$ measured at room temperature under Ar atmosphere. $\lambda_{T C}$ is thermal conductivity $(\mathrm{W} / \mathrm{m} . \mathrm{K}), k$ is thermal diffusivity $\left(\mathrm{mm}^{2} / \mathrm{s}\right)$, and $C$ is the heat capacity per unit volume $\left(\mathrm{MJ} / \mathrm{m}^{3} \cdot \mathrm{K}\right)$.

\begin{tabular}{llll}
\hline & \multicolumn{1}{c}{$\begin{array}{c}\lambda_{T C} \\
{[\mathbf{W} / \mathbf{m} \cdot \mathbf{K}]}\end{array}$} & $\begin{array}{c}\boldsymbol{K} \\
{\left[\mathbf{m m}^{2} / \mathbf{s}\right]}\end{array}$ & $\begin{array}{c}\boldsymbol{C} \\
{\left[\mathbf{M J} / \mathbf{m}^{\mathbf{3}} \cdot \mathbf{K}\right]}\end{array}$ \\
\hline $\mathbf{M g H}_{2}$ & $2.08(3)$ & $1.53(7)$ & $1.37(8)$ \\
\hline $\mathbf{M g H}_{\mathbf{0 . 9 5}} \mathbf{F}_{\mathbf{0 . 0 5}}$ & $1.297(6)$ & $0.98(4)$ & $1.32(5)$ \\
\hline $\mathbf{M g H}_{0.85} \mathbf{F}_{0.15}$ & $0.717(3)$ & $0.49(1)$ & $1.46(3)$ \\
\hline $\mathbf{M g H}_{\mathbf{0 . 7 0}} \mathbf{F}_{0.30}$ & $0.584(2)$ & $0.42(1)$ & $1.39(3)$ \\
\hline $\mathbf{M g H}_{\mathbf{0 . 5 0}} \mathbf{F}_{\mathbf{0 . 5 0}}$ & $0.481(3)$ & $0.41(2)$ & $1.17(4)$ \\
\hline $\mathbf{M g F}_{2}$ & $0.676(6)$ & $0.43(1)$ & $1.58(3)$ \\
\hline
\end{tabular}

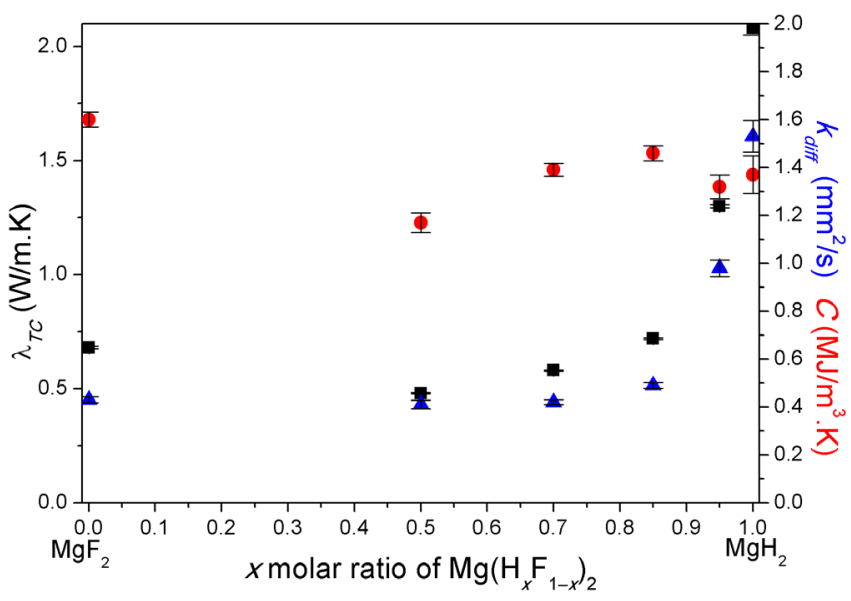

Figure 5. Thermal transport properties of $\mathrm{Mg}\left(\mathrm{H}_{x} \mathrm{~F}_{1-x}\right)_{2}$. Thermal conductivity (black square), thermal diffusivity (blue triangle) and volumetric heat capacity (red circle) measured at RT under Ar atmosphere.

depending on conditions. ${ }^{51,52}$ It was determined that an optimal value of $\sim 5 \mathrm{~W} / \mathrm{m} . \mathrm{K}$ for a hydrogenated sample of $\mathrm{LaNi}_{4.9} \mathrm{Al}_{0.3}$ allows for optimal hydrogen absorption kinetics, while a larger value only has a minor incremental influence. ${ }^{53}$ Therefore, to gain technological application, it may be beneficial to enhance $\lambda_{T C}$ by the addition a material such as exfoliated natural graphite. ${ }^{9,21}$

\section{CONCLUSIONS}

This study has detailed a thorough characterisation of fluorine substituted magnesium hydride $\left(\mathrm{Mg}\left(\mathrm{H}_{x} \mathrm{~F}_{1-x}\right)_{2}\right.$ where $x=1,0.95$, $0.85,0.70,0.50,0)$, a class of materials that have potential application as hydrogen storage or thermal energy storage materials. The physical properties of these solid solutions have been studied by powder X-ray diffraction, inelastic neutron spectroscopy, and thermal conductivity. In addition, these measurements have been verified by density functional theory calculations.

Using these techniques, a number of trends have been identified that can be correlated to the random substitution of $\mathrm{F}^{-}$into the crystal lattice. The tetragonal unit cell volume expands in a quadratic trend by $5.4 \%$ from $\mathrm{MgH}_{2}$ to $\mathrm{MgF}_{2}$. This expansion is isotropic in nature with a $2.3 \%$ expansion in the $a$-axis compared to $c$-axis. This is mirrored with a preferred extension of the axial $\mathrm{Mg}-\mathrm{H}(\mathrm{F})$ bond distances over the equatorial bond distances. Overall, the addition of $\mathrm{F}^{-}$increases the average $\mathrm{Mg}-\mathrm{H}(\mathrm{F})$ bond strength, which increases the thermal stability of the material, making fluorine rich $\mathrm{Mg}-\mathrm{H}-\mathrm{F}$ compounds efficient thermal energy storage materials. Despite the reduction in hydrogen-storage capacity, the increased thermal stability will permit hydrogen cycling at higher temperatures and therefore greater efficiency for thermal energy storage.

Inelastic neutron diffraction data has been collected for the first time for fluorine substituted magnesium hydride. Along with the simulated GDOS data from density functional theory calculations, these materials have exhibited a trend in vibrational frequencies and intensities from $\mathrm{MgH}_{2}$ towards $\mathrm{MgF}_{2}$ that is in line with the expansion in lattice parameters and bond distances.

The thermal transport properties, including thermal conductivity, diffusivity and heat capacity, for the range of $\mathrm{Mg}\left(\mathrm{H}_{x} \mathrm{~F}_{1-x}\right)_{2}$ samples was also determined. This was the first time that $\mathrm{MgH}_{2}$ and $\mathrm{MgF}_{2}$ have been measured under the same conditions which has allowed a direct comparison with the fluorine substituted analogues.

\section{ASSOCIATED CONTENT}

\section{Supporting Information.}

Quantitative Rietveld analysis of SR-XRD data for $\mathrm{Mg}\left(\mathrm{H}_{x} \mathrm{~F}_{1-x}\right)_{2}$ solid solutions; thermodynamic and crystallographic parameters derived from DFT calculations; NEXAFS experimental, results and discussion.

This material is available free of charge via the Internet at http://pubs.acs.org."

\section{AUTHOR INFORMATION}

Corresponding Author

*E-mail: terry humphries81@hotmail.com

\section{Author Contributions}

All authors have given approval to the final version of the manuscript.

\section{Notes}

The authors declare no competing financial interest.

\section{ACKNOWLEDGMENT}

The authors CEB, TDH, MVS and MP acknowledge the financial support of the Australian Research Council (ARC) for ARC Linkage grants LP120101848 and LP150100730. CEB, TDH, MP and MVS acknowledge financial support from the Department of Industry Innovation and Science for the 2019 Global Innovation Linkage (GIL73589) grant. CEB and MP acknowledge the financial support of the ARC for DP150101708. MP acknowledges his ARC Future Fellowship FT160100303. JY acknowledge the support from ANSTO for a Postdoctoral Fellowship. The authors also acknowledge funding from the ANSTO, which enabled research at the powder diffraction beamline at the Australian Synchrotron and Inelastic Neutron Spectroscopy to be undertaken on Pelican. The authors would also like to acknowledge Dr J.P. Veder for collecting the NEXAFS data. 


\section{REFERENCES}

1. Züttel, A.; Remhof, A.; Borgschulte, A.; Friedrichs, O., Hydrogen: the future energy carrier. Phil. Trans. R. Soc. A 2010, 368 (1923), 3329-3342.

2. Makepeace, J. W.; He, T.; Weidenthaler, C.; Jensen, T. R.; Chang, F.; Vegge, T.; Ngene, P.; Kojima, Y.; de Jongh, P. E.; Chen, P.; David, W. I. F., Reversible ammonia-based and liquid organic hydrogen carriers for high-density hydrogen storage: Recent progress. Int. J. Hydrogen Energy 2019, 44 (15), 7746-7767.

3. Crivello, J.-C.; Denys, R. V.; Dornheim, M.; Felderhoff, M.; Grant, D. M.; Huot, J.; Jensen, T. R.; de Jongh, P.; Latroche, M.; Walker, G. S.; Webb, C. J.; Yartys, V. A., Mg-based compounds for hydrogen and energy storage. Appl. Phys. A 2016, 122 (2), 85.

4. Webb, C. J., A review of catalyst-enhanced magnesium hydride as a hydrogen storage material. J. Phys. Chem. Solids 2015, 84, 96-106.

5. $\quad$ Yartys, V. A.; Lototskyy, M. V.; Akiba, E.; Albert, R.; Antonov, V. E.; Ares, J. R.; Baricco, M.; Bourgeois, N.; Buckley, C. E.; Bellosta von Colbe, J. M.; Crivello, J. C.; Cuevas, F.; Denys, R. V.; Dornheim, M.; Felderhoff, M.; Grant, D. M.; Hauback, B. C.; Humphries, T. D.; Jacob, I.; Jensen, T. R.; de Jongh, P. E.; Joubert, J. M.; Kuzovnikov, M. A.; Latroche, M.; Paskevicius, M.; Pasquini, L.; Popilevsky, L.; Skripnyuk, V. M.; Rabkin, E.; Sofianos, M. V.; Stuart, A.; Walker, G.; Wang, H.; Webb, C. J.; Zhu, M., Magnesium Based Materials for Hydrogen Based Energy Storage: Past, Present and Future. Int. J. Hydrogen Energy 2019, 44 (15), 7809-7859.

6. Humphries, T. D.; Sheppard, D. A.; Buckley, C. E., Recent advances in the 18-electron complex transition metal hydrides of $\mathrm{Ni}$, Fe, Co and Ru. Coord. Chem. Rev. 2017, 342, 19-33.

7. Paskevicius, M.; Sheppard, D. A.; Buckley, C. E., Thermodynamic changes in mechanochemically synthesized magnesium hydride nanoparticles. J. Am. Chem. Soc. 2010, 132 (14), 5077-5083

8. DOE Technical targets for onboard hydrogen storage for light-duty vehicles. https://www.energy.gov/eere/fuelcells/doetechnical-targets-onboard-hydrogen-storage-light-duty-vehicles (accessed 19/03/2019).

9. $\quad$ Dong, D.; Humphries, T. D.; Sheppard, D. A.; Stansby, B.; Paskevicius, M.; Sofianos, M. V.; Chaudhary, A. L.; Dornheim, M.; Buckley, C. E., Thermal optimisation of metal hydride reactors for thermal energy storage applications. Sustain. Energy Fuels 2017, 1 (8), 1820-1829.

10. Tortoza, M. S.; Humphries, T. D.; Sheppard, D. A.; Paskevicius, M.; Rowles, M. R.; Sofianos, M. V.; Aguey-Zinsou, K. F.; Buckley, C. E., Thermodynamics and performance of the Mg-H-F system for thermochemical energy storage applications. Phys. Chem. Chem. Phys. 2018, 20 (4), 2274-2283.

11. Pinatel, E. R.; Corno, M.; Ugliengo, P.; Baricco, M., Effects of metastability on hydrogen sorption in fluorine substituted hydrides. J. Alloys Compd. 2014, 615, S706-S710.

12. Varunaa, R.; Ravindran, P., Phase stability, phase mixing, and phase separation in fluorinated alkaline earth hydrides. $J$. Phys. Chem. C 2017, 121 (40), 21806-21820.

13. Bortz, M.; Bertheville, B.; Böttger, G.; Yvon, K., Structure of the high pressure phase $\gamma-\mathrm{MgH} 2$ by neutron powder diffraction. Journal of Alloys Compounds 1999, 287 (1-2), L4-L6.

14. Corey, R. L.; Ivancic, T. M.; Shane, D. T.; Carl, E. A.; Bowman, R. C.; Bellosta von Colbe, J. M.; Dornheim, M.; Bormann, R.; Huot, J.; Zidan, R.; Stowe, A. C.; Conradi, M. S., Hydrogen motion in magnesium hydride by NMR. J. Phys. Chem. C 2008, 112 (49), 19784-19790.

15. Senegas, J.; Pezat, M.; Darnaudery, J. P.; Darriet, B., Study by NMR on localization and movements of protons in $\mathrm{MgH}_{2}$ and $\mathrm{Mg}_{2} \mathrm{NiH}_{4}$ hydrides. J. Phys. Chem. Solids 1981, 42 (1), 29-35.

16. Felsteiner, J.; Heilper, M.; Gertner, I.; Tanner, A. C.; Opher, R.; Berggren, K. F., Compton scattering study of the electronic structure of magnesium hydride. Phys. Rev. B 1981, 23 (10), 51565162 .

17. Santisteban, J. R.; Cuello, G. J.; Dawidowski, J.; Fainstein, A.; Peretti, H. A.; Ivanov, A.; Bermejo, F. J., Vibrational spectrum of magnesium hydride. Phys. Rev. B 2000, 62 (1), 37-40.
18. Schimmel, H. G.; Johnson, M. R.; Kearley, G. J.; RamirezCuesta, A. J.; Huot, J.; Mulder, F. M., The vibrational spectrum of magnesium hydride from inelastic neutron scattering and density functional theory. Mater. Sci. Eng. B. 2004, 108 (1-2), 38-41.

19. Schimmel, H. G.; Johnson, M. R.; Kearley, G. J.; RamirezCuesta, A. J.; Huot, J.; Mulder, F. M., Structural information on ball milled magnesium hydride from vibrational spectroscopy and ab-initio calculations. J. Alloys Compd. 2005, 393 (1), 1-4.

20. Hanada, N.; Ichikawa, T.; Isobe, S.; Nakagawa, T.; Tokoyoda, K.; Honma, T.; Fujii, H.; Kojima, Y., X-ray absorption spectroscopic study on valence state and local atomic structure of transition metal oxides doped in $\mathrm{MgH}_{2}$. J. Phys. Chem. C 2009, 113 (30), 13450-13455.

21. Chaise, A.; de Rango, P.; Marty, P.; Fruchart, D.; Miraglia, S.; Olivès, R.; Garrier, S., Enhancement of hydrogen sorption in magnesium hydride using expanded natural graphite. Int. J. Hydrogen Energy 2009, 34 (20), 8589-8596.

22. Shim, J.-H.; Park, M.; Lee, Y. H.; Kim, S.; Im, Y. H.; Suh, J.-Y.; Cho, Y. W., Effective thermal conductivity of $\mathrm{MgH}_{2}$ compacts containing expanded natural graphite under a hydrogen atmosphere. Int. J. Hydrogen Energy 2014, 39 (1), 349-355.

23. Wallwork, K. S.; Kennedy, B. J.; Wang, D., The High Resolution Powder Diffraction Beamline for the Australian Synchrotron. Synchrotron Radiation Instrumentation, Pts 1 and 2 2007, 879 (1), 879-+.

24. Schmitt, B.; Bronnimann, C.; Eikenberry, E. F.; Gozzo, F.; Hormann, C.; Horisberger, R.; Patterson, B., Mythen Detector System. Nucl Instrum Meth A 2003, 501 (1), 267-272.

25. Young, R. A.; Young, R. A., The Rietveld Method. Oxford University Press: 1995.

26. Loopstra, B. O.; Rietveld, H. M., The structure of some alkaline-earth metal uranates. Acta Crysta. B 1969, 25 (4), 787-791.

27. Coelho, A. A., TOPAS and TOPAS-Academic: An optimization program integrating computer algebra and crystallographic objects written in C Plus. J. Appl. Crystallogr. 2018, 51 (1), 210-218.

28. Richard, D.; Ferrand, M.; Kearley, G. J., Analysis and visualisation of neutron-scattering data. J. Neutron Res. 1996, 4 (1-4), 33-39.

29. Mutka, H.; Koza, M. M.; Johnson, M. R.; Hiroi, Z.; Yamaura, J.-I.; Nagao, Y., Generalized density-of-states and anharmonicity of the low-energy phonon bands from coherent inelastic neutron scattering response in the pyrochlore osmates $A \mathrm{Os}_{2} \mathrm{O}_{6}(A=\mathrm{K}$, Rb, Cs). Phys. Rev. B 2008, 78 (10), 104307.

30. Kresse, G.; Furthmuller, J., Efficient iterative schemes for ab initio total-energy calculations using a plane-wave basis set. Phys. Rev. B 1996, 54 (16), 11169-11186.

31. Perdew, J. P.; Burke, K.; Ernzerhof, M., Generalized gradient approximation made simple. Phys. Rev. Lett. 1996, 77 (18), 3865-3868.

32. Kresse, G.; Joubert, D., From ultrasoft pseudopotentials to the projector augmented-wave method. Phys. Rev. B 1999, 59 (3), $1758-1775$.

33. Togo, A.; Tanaka, I., First principles phonon calculations in materials science. Scr. Mater. 2015, 108, 1-5.

34. Bansal, D.; Hong, J.; Li, C. W.; May, A. F.; Porter, W.; Hu, M. Y.; Abernathy, D. L.; Delaire, O., Phonon anharmonicity and negative thermal expansion in SnSe. Phys. Rev. B 2016, 94 (5), 054307.

35. NIST Center for Neutron Research.
https://www.ncnr.nist.gov/resources/n-lengths/list.html (accessed November 2, 2019).

36. Baur, W. H., The rutile type and its derivatives Crystallography Reviews 2007, 13 (1), 65-113.

37. Haines, J.; Léger, J. M.; Gorelli, F.; Klug, D. D.; Tse, J. S.; Li, Z. Q., X-ray diffraction and theoretical studies of the highpressure structures and phase transitions in magnesium fluoride. Phys. Rev. B 2001, 64 (13), 134110.

38. Ramesh Babu, K.; Bheema Lingam, C.; Auluck, S.; Tewari, S. P.; Vaitheeswaran, G., Structural, thermodynamic and optical properties of MgF2 studied from first-principles theory. J. Solid State Chem. 2011, 184 (2), 343-350. 
39. Noritake, T.; Aoki, M.; Towata, S.; Seno, Y.; Hirose, Y.; Nishibori, E.; Takata, M.; Sakata, M., Chemical bonding of hydrogen in $\mathrm{MgH}$ 2. Appl. Phys. Lett. 2002, 81 (11), 2008-2010.

40. Vidal, J. P.; Vidal-Valat, G.; Galtier, M.; Kurki-Suonio, K., X-ray study of the charge distribution in MgF2. Acta Crystallogr A 1981, 37 (6), 826-837.

41. Denton, A. R.; Ashcroft, N. W., Vegard's law. Phys. Rev. A 1991, 43 (6), 3161-3164.

42. Humphries, T. D.; Sheppard, D. A.; Rowles, M. R.; Sofianos, M. V.; Buckley, C. E., Fluoride Substitution in Sodium Hydride for Thermal Energy Storage Applications. J. Mater. Chem. A 2016, 4 (31), 12170-12178.

43. Gangrade, A. S.; Varma, A. A.; Gor, N. K.; Shriniwasan, S.; Tatiparti, S. S. V., The dehydrogenation mechanism during the incubation period in nanocrystalline $\mathrm{MgH}$ 2. Phys. Chem. Chem. Phys. 2017, 19 (9), 6677-6687.

44. Cox, J. D.; Wagman, D. D.; Medvedev, V. A., CODATA key values for thermodynamics. Hemisphere Pub. Corp.: New York, 1989.

45. Sheppard, D. A.; Paskevicius, M.; Buckley, C. E., Thermodynamics of hydrogen desorption from $\mathrm{NaMgH}_{3}$ and its application as a solar heat storage medium. Chem. Mater. 2011, 23 (19), 4298-4300.
46. Koyama, K., Thermal conductivity of magnesium fluoride between $25^{\circ}$ and $900^{\circ}$ C. J. Am. Ceram. Soc. 1969, 52 (4), 222-224.

47. Camirand, C. P., Measurement of thermal conductivity by differential scanning calorimetry. Thermochim. Acta 2004, 417 (1), 14.

48. Lang, J.; Eagles, M.; Conradi, M. S.; Huot, J., Hydrogenation rate limiting step, diffusion and thermal conductivity in cold rolled magnesium hydride. J. Alloys Compd. 2014, 583, 116-120.

49. Kittel, C.; McEuen, P.; McEuen, P., Introduction to solid state physics. Wiley New York: 1976; Vol. 8.

50. Sundqvist, B.; Andersson, O., Thermal conductivity and phase diagrams of some potential hydrogen storage materials under pressure. Int. J. Thermophys. 2009, 30 (4), 1118-1129.

51. Beattie, S. D.; Harris, A.; Levchenko, A.; Rudolph, J.; Willson, C. D.; McGrady, G. S., Thermal conductivity and specific heat measurements of metal hydrides. In ITCC Proceedings, 2009; Vol. 11.

52. Sulic, M.; Cai, M.; Kumar, S., Cycling and engineering properties of highly compacted sodium alanate pellets. Int. J. Hydrogen Energy 2012, 37 (20), 15187-15195.

53. Choi, H.; Mills, A. F., Heat and mass transfer in metal hydride beds for heat pump applications. Int. J. Heat Mass Transfer 1990, 33 (6), 1281-1288. 
TOC Graphic

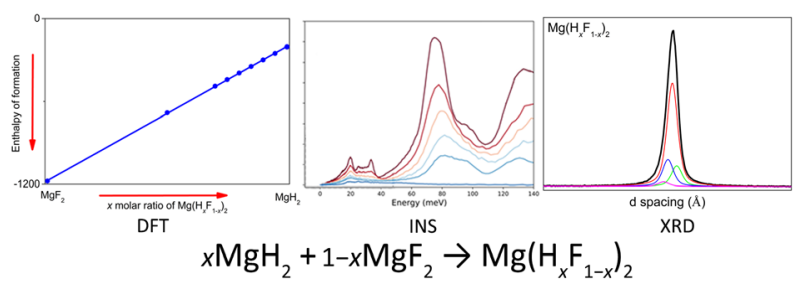

